\title{
Local time-averaged gas holdup in fluidized bed reactor using gamma ray computed tomography technique (CT)
}

\author{
Abdelsalam Efhaima ${ }^{1}$ Muthanna H. Al-Dahhan ${ }^{1}$
}

Received: 30 August 2014/ Accepted: 6 July 2015/Published online: 17 July 2015

(c) The Author(s) 2015. This article is published with open access at Springerlink.com

\begin{abstract}
Many invasive and non-invasive techniques have been used to analyze the hydrodynamics of fluidized beds. In this study, the effect of superficial gas velocity and bed particle density on the hydrodynamics of gas-solid fluidized beds was investigated by using a cylindrical plexiglas fluidized bed column, $14 \mathrm{~cm}$ in diameter. Air at room temperature was used as the fluidizing gas and two different Geldart type-B particles were used: glass beads and copper particles with material densities of 2.5 and $5.3 \mathrm{~g} / \mathrm{cm}^{3}$, respectively, with the same size particle, $210 \mu \mathrm{m}$. To measure the time-averaged cross-sectional gas and solid holdup distribution, gamma ray computed tomography was used for the first time as a non-invasive technique instead of using X-rays (due to the height attenuation of the copper particles). The results show that gas holdup increases by increasing the superficial gas velocity, and decreasing the particle density increases the gas holdup in the bed.
\end{abstract}

Keywords Fluidized beds · Hydrodynamics - Gamma ray computed tomography $\cdot$ Gas holdup · Solid holdup

\section{Introduction}

Contacting solid particles with gases is often a necessity in many industrial operations. The gas-solid fluidized bed reactor is one of the most widely employed gas-solid

Abdelsalam Efhaima

ayed67@mst.edu

1 Department of Chemical and Biochemical Engineering, Missouri University of Science and Technology, 110 Bertelsmeyer Hall, 1101 N. State St., Rolla, MO 65409, USA reactors. Fluidized beds provide good mixing, height mass, and heat transfer rates between gas and solid particles, low pressure drop, approximately uniform temperature distribution, and the ability to fluidize many particle types of different densities and sizes. Due to these advantages fluidized bed reactors (FBRs) are extensively used in many industrial applications such as drying granular materials, cooling of fertilizers, coal combustion and gasification, chemical process, gas phase polymerization, and for various uses in the pharmaceutical and petroleum industries [1].

Phosphate rock deposits vary in composition. To prepare the phosphate rock for making phosphoric acid, which is then utilized in subsequent reactions (i.e., the manufacture of triple superphosphate and for other valuable products), it is necessary to beneficiate the phosphate rock by removing certain impurities. Very often, a substantial amount of limestone $\left(\mathrm{CaCO}_{3}\right)$ is associated with the phosphate rock, and a calcining operation is indicated to drive off the $\mathrm{CO}_{2}$. One commercial method for the calcination of phosphate rock employs a fluidized bed reactor. In this process, finely divided phosphate rock is dried in the first fluidized bed and then transported to a second fluidized bed, where calcination takes place. Drying is very important process, as effective moisture removal defines the process' efficiency and the subsequent unit operations. The drying process can be characterized as a gas-solid fluidized bed system.

The performance of these multiphase fluidized bed reactors greatly depends on their hydrodynamic properties, therefore, understanding the hydrodynamics behavior of fluidized bed reactors is essential for their proper design, effective scale-up, and efficient operation.

Although considerable research efforts have focused on the hydrodynamics of the fluidized bed, such as studying 
the shape and size of bubbles/void, the solid concentration, solid holdup distribution, gas holdup distribution at different gas velocities, and turbulence parameters (Reynolds stress, normal stresses, turbulent kinetic energy, turbulent eddy diffusivities, etc.). The lack of accurate, instantaneous, and simultaneous techniques for measurement along the bed cross section prevents a precise description of the dynamic flow behavior in the fluidized bed.

In order to obtain deeper insight into a highly complex gas and solid flow system, detailed and accurate experimental works are obviously important. The hydrodynamic properties in a fluidized bed can be measured using invasive techniques, such as the capacitance probe and the optical fiber probe. These approaches cannot adequately monitor internal flow features. Also, since fluidization is a dynamic process, invasive monitoring methods can influence the internal flow, In addition, it is, difficult to measure the simultaneous flow variations across the bed with such tools. Instead, such measurements need to be carried out with non-invasive techniques, such as the pressure transducer and tomography techniques, e.g., electrical capacitance tomography (ECT), x-ray computed tomography, and $\gamma$-ray computed tomography (CT). Among various tomography techniques, the $\gamma$-ray computed tomography technique exhibits versatility for practical usage for the imaging of multiphase flow systems and suitability for height attenuation particles, as well as for small and large vessels.

One of the earliest applications of computed tomography (CT) to two-phase flow was the study by Fincke et al. [2]; they obtained the density distributions for a horizontal air-water flow in a 3-inch diameter pipe. Nine detectors arranged in an arc were used and 21 views at $9^{\circ}$ increments were obtained for a total of 189 data values. From this data they were able to obtain density maps corresponding to different flow regimes.

Seville et al. [3] used a single-source single-detector arrangement capable of translation and rotation about the test section. They obtained the voidage structure in the jet region of a fluidized bed. The total time for scanning one section was 6-7 h.

Banholzer et al. [4], used a medical x-ray CT scanner to conduct a feasibility study on a model fluidized bed (43$\mathrm{mm}$ ID and 150-mm long) under a range of experimental conditions. A spatial resolution of $1.5 \mathrm{~mm}$ and a density resolution of better than $30 \mathrm{~kg} \mathrm{~m}^{3}$ were achieved.

Grassler and Wirth [5], used x-ray computed tomography $(\mathrm{CT})$ imaging to determine the solid concentration in a 0.19-m diameter circulation fluidized bed with $50-70 \mu \mathrm{m}$ glass beads as the bed material, they showed that the radial solid concentration exhibited a parabolic shape with a maximum concentration close to the wall of the reactor and a minimum concentration in the center of the bed.
X-ray computed tomography (CT) imaging was used by Escudero et al. [6] to determine bed height and material density effects on fluidized bed hydrodynamics in a $10.2 \mathrm{~cm}$ fluidized bed, using low-density materials. They used three different materials Geldart type-B particles (glass beads, ground walnut shell, and ground corncob) with material densities of $2.6,1.3$, and $1 \mathrm{~g} / \mathrm{cm}^{3}$, respectively. Results showed that decreasing the bed density increased the gas holdup in the bed.

Escudero et al. [6], also studied the profiles of solid holdup for low-density materials. By treating three different Geldart type-B particles at various superficial gas velocities at specific H/D ratios it was found that the solid holdup decreased by increasing the superficial gas velocity.

Zhu et al. [7] determined the solid volumetric fraction $\left(1-\varepsilon_{\mathrm{g}}\right)$ in gas-solid systems for bubbling and turbulent fluidization regimes. The turbulent regime showed that solid concentrations were not uniform in the axial or radial direction. In the bubbling regime the non-uniformity increased as the superficial gas velocity increased.

$\mathrm{Du}$ et al. [8] measured the solid concentration for bubbling and turbulent fluidized beds. Results showed that at high superficial gas velocities, especially in the turbulent regime, the cross section solids holdup exhibited a radially symmetric distribution, which was not the case for the bubbling regime. At low superficial gas velocity in the bubbling regime, dispersed bubble produced a lower solid concentration (high solid holdup) in the center of the bed.

Mabrouk et al. [9] studied the axial and radial profiles of the solids holdup using an optical fiber probe and radioactive particle tracking (RPT) technique. The axial solids holdup profiles obtained by an optical fiber needle probe and radioactive particle tracking technique show a quasi-linear profile.

\section{Experimental set-up}

A cold-flow fluidized bed was used in this study, with outside diameter $14 \mathrm{~cm}$ and height $168 \mathrm{~cm}$. A schematic diagram of the set-up used in this study is provided in Fig. 1. The fluidized bed column was constructed from plexiglas and consisted of two pieces (column and cone) attached to a plenum base. Connected from the top with an upper section that had a diameter of $42 \mathrm{~cm}$ and was $84 \mathrm{~cm}$ tall, this upper section of the fluidized bed had a larger diameter to reduce the superficial gas velocity of the gas phase and thus enhance the solids separation. The column sat at the top of a stainless steel base. A porous polyethylene sheet with a pore size of $40 \mu \mathrm{m}$ was employed as the gas distributor. The plenum was located at the bottom. The fluidized bed column was electrically ground to minimize electrostatic effects. Air under ambient conditions 
Fig. 1 Schematic of the coldflow fluidized bed reactor

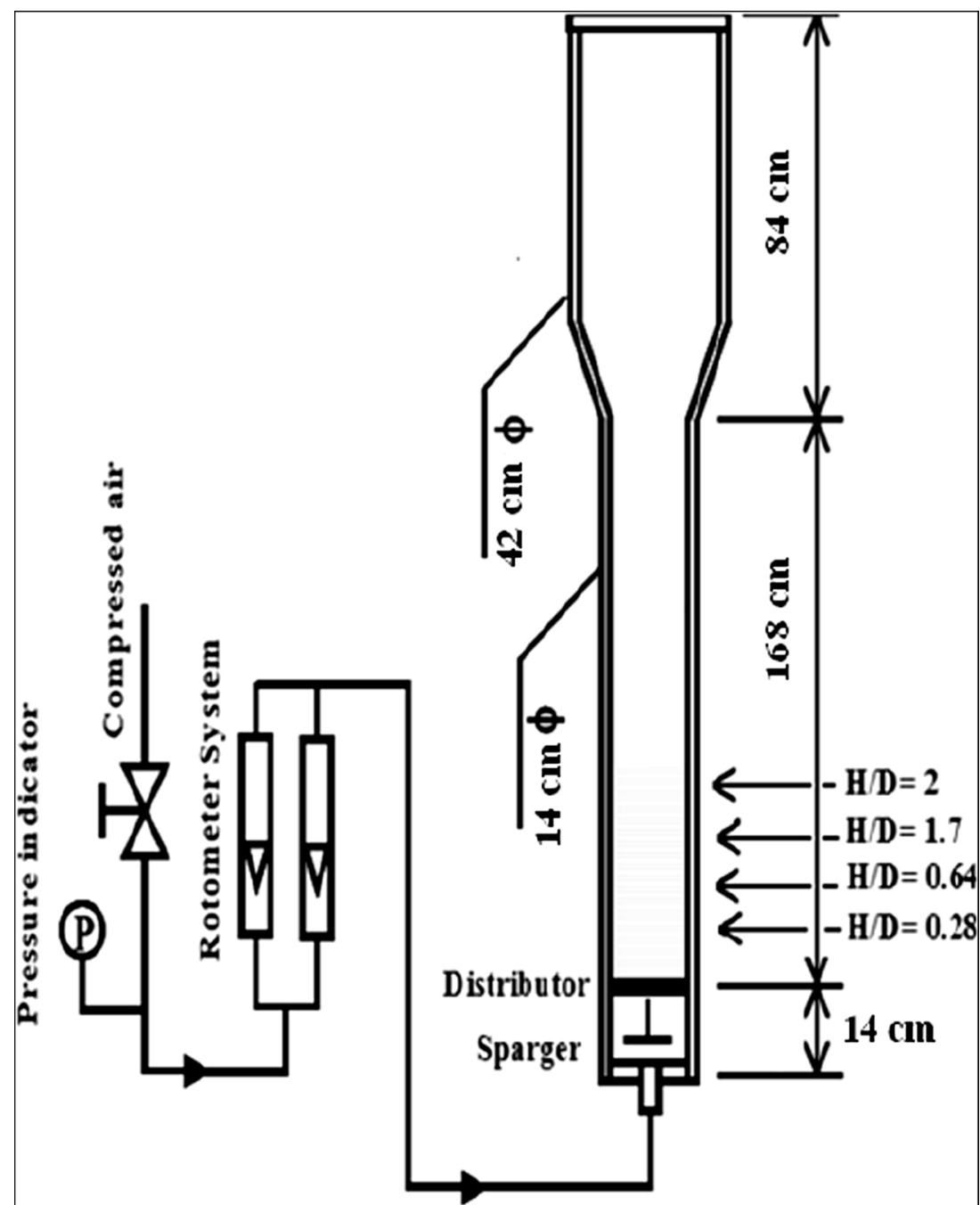

was the fluidizing gas. The gas flow rate to the unit was controlled by rotameters.

\section{Measurement techniques}

\section{Computed tomography (CT)}

\section{CT facility and measurement procedure}

The DSCT scanner at Missouri University of Science and Technology which was developed by Varma [10] with support from the Department of Energy (DOE) was used in this work to determine the time-averaged cross-sectional variation of gas and solid holdups at the operating conditions previously outlined (see Table 1). The CT used in this study was based on a newer generation of double fan-beam scanning configuration. Details on both the hardware and the software used in this study have been described by Varma and Al-Dahhan [11], Varma et al. [12]. A photograph of the CT facility used in this study is pictured in Fig. 2.

The scanner's configuration consisted of two independent gamma ray sources, encapsulated Cesium (C-137) and Cobalt (Co-60), with initial strengths of $(\sim 250 \mathrm{mCi})$ and $(50 \mathrm{mCi})$, respectively (dual source CT), as well as two arrays of fifteen $\mathrm{NaI}$ scintillation detectors located opposite each source for imaging the phases. The sources and detectors are built on a rotary plate that moves them together $360^{\circ}$ around the studied object, providing 197 views in each scan and 21 projections in each view. The entire assembly could be moved up and down along the column to scan the object at different axial positions (see Fig. 3). Each detector consists of a cylindrical NaI crystal measuring $2^{\prime \prime}$ in both diameter and length, a photomultiplier and electronics.

Each of these detectors was collimated with a lead collimator. Collimators had approximately an open aperture $2 \mathrm{~mm} \times 2$. This aperture reduces the crystal's 
Table 1 Summary of the bed materials and their properties

\begin{tabular}{lll}
\hline Material properties & Glass beads & $\begin{array}{l}\text { Copper } \\
\text { particles }\end{array}$ \\
\hline Particle diameter $(\mu \mathrm{m})$ & 210 & 210 \\
Bed height $(\mathrm{H} / \mathrm{D})$ & 2 & 2 \\
Particle density $\left(\mathrm{g} / \mathrm{cm}^{3}\right)$ & 2.5 & 5.3 \\
Minimum fluidization velocity $(\mathrm{cm} / \mathrm{s})$ & 12 & 20 \\
\hline
\end{tabular}

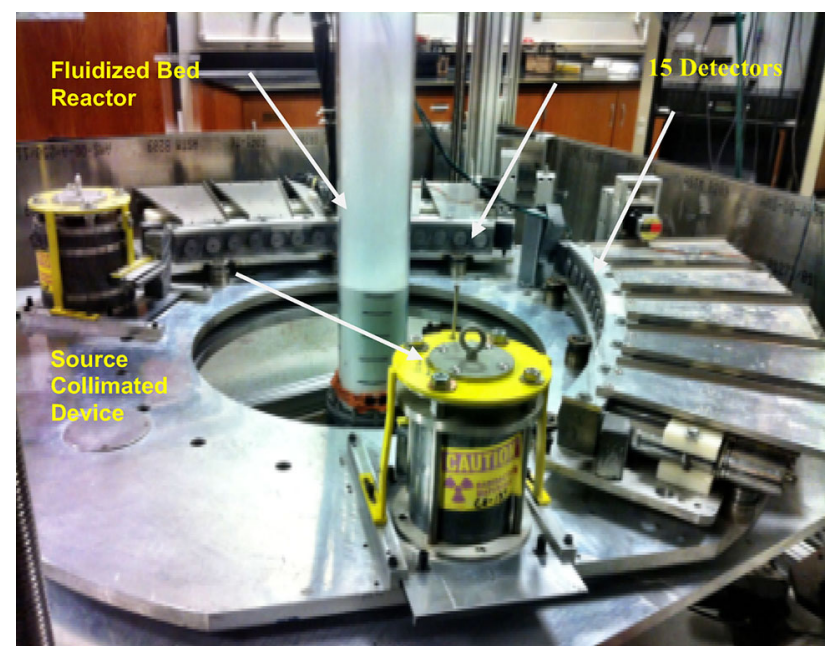

Fig. 2 The CT with a 0.14-m fluidized bed reactor used in this study

effective exposed area to a rectangular region and the counts received by the detectors are limited to what is incident on this aperture. CT scan sampling rate was 60 samples at $10 \mathrm{~Hz}$, which took approximately $7.2 \mathrm{~s}$ to finish a 50 projection and $8.25 \mathrm{~h}$ to finish a comprehensive scan.

\section{Steps of scanning}

In this study, CT experiments were performed under a twophase condition (gas and solid). To measure the crosssectional distribution of each phase, the Cesium (Cs-137) source was used to measure the phase holdup distribution. The fluidized bed column's cross section was divided into $n \times m$ square pixels and the following CT scans were performed:

1. Scanning the column empty as reference CT scan.

2. Scanning the column filled with solids (glass beads).

3. Scanning the column at normal gas-solid operations at the desired conditions.

The attenuations were measured along a number of beams paths through the column from different angles. Based on Beer-Lambert's Law, the attenuation through the materials along the beam path is expressed as follows:

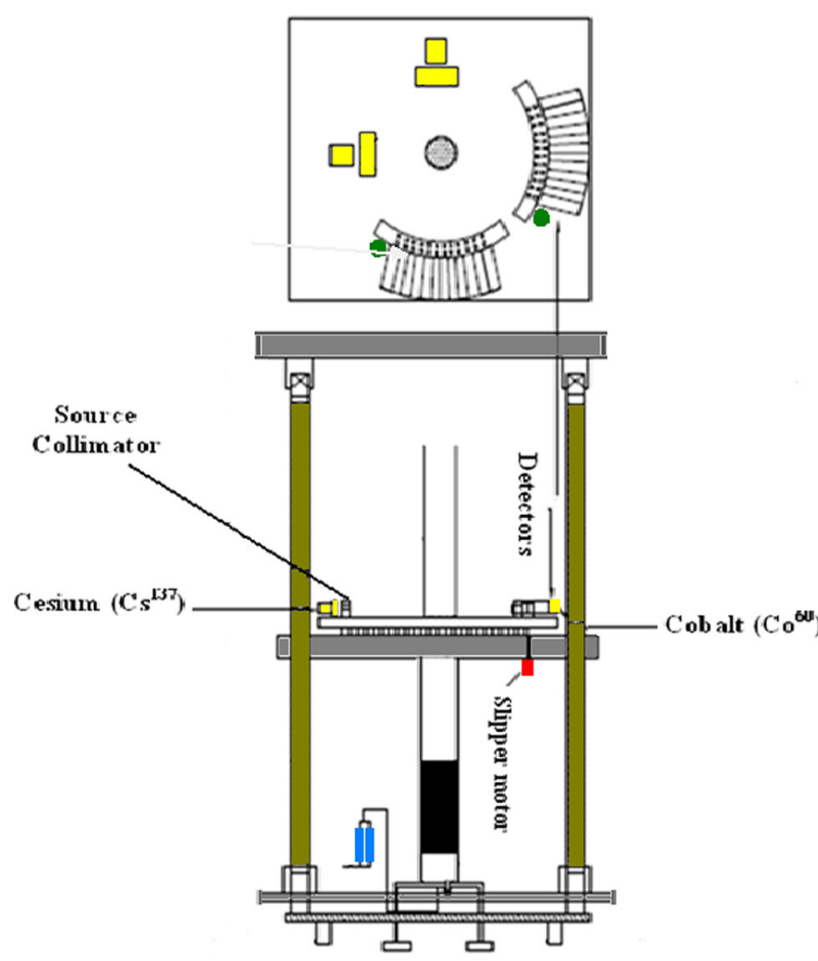

Fig. 3 Schematic diagram of dual-source CT unit

$T=\frac{I}{I_{0}} \cdot \exp (-\mu \rho l)$

where $(T)$ is the transmission ratio, $\left(I_{0)}\right.$ is the incident radiation, $(I)$ is the detected radiation, $(\mu)$ is the mass attenuation coefficient, $(\rho)$ is the medium density, $(l)$ is the path length through the medium. The measured quantity $\mathrm{ln}$ $\left(I / I_{0}\right)$ (called $A$, for simplicity) is equal to the integral sum of the attenuation through the material along the beam path.

$A=\ln \frac{I}{I_{0}}=\mu \rho l$

To obtain statistically significant results and to reduce the effect of position, the CT scans were obtained by scanning $360^{\circ}$ around the column for a total scanning time of about $8 \mathrm{~h}$. If the scanned cross section is divided into pixels or cells and the medium comprises two materials (gas and solid), $\left(\mu_{\mathrm{s}}\right)$ is mass attenuation coefficient for solid, $\left(\mu_{\mathrm{g}}\right)$ is mass attenuation coefficient for gas, $\rho$ is the medium density, $\left(\rho_{\mathrm{s}}\right)$ solid density, $\left(\rho_{\mathrm{g}}\right)$ gas density, and thickness $\left(l_{\mathrm{g}}\right),\left(l_{\mathrm{s}}\right)$ for gas and solid phases, respectively, then the total attenuation is

$A=\rho_{s} \mu_{s} l_{s}+\rho_{g} \mu_{g} l_{g}$

where $L_{i j}=L s,_{i j}+L g_{, i j}, L s,_{i j}=\varepsilon_{s, i j} L_{i j}$ and $L g_{, \mathrm{ij}}=\varepsilon_{g, i j} L_{i j}$, where $L_{i j}$ is the total length between the source and the detector. $\varepsilon_{g, i j}, \varepsilon_{s, i j}$ are the holdups (volume fractions) for the gas and solid phases. 
$A=\left[\rho_{s} \mu_{s} \varepsilon_{s, i j}+\rho_{g} \mu_{g} \varepsilon_{g, i j}\right] \cdot L_{i j}$.

The summation of the holdups is equal to unity (i.e., $\left.\varepsilon_{g, i j}=1-\varepsilon_{s, i j}\right)$.

$A_{s-g, i j}=\left[\rho_{s} \mu_{s} \varepsilon_{s, i j}+\rho_{g} \mu_{g}\left(1-\varepsilon_{s, i j}\right)\right] \cdot L_{i j}$

$A_{s-g, i j}=\left[\rho_{s} \mu_{s} \varepsilon_{s, i j}+\rho_{g} \mu_{g}\left(1-\varepsilon_{s, i j}\right)\right] \cdot L_{i j}$.

Since $\rho_{\mathrm{g}} \ll \rho_{\mathrm{s}}$, the attenuation caused by the gas phase is negligible compared to the solids, and $L$ is common for all $A_{\mathrm{s}}$. Hence, solids holdup for the line averaged measurement can be written as follows:

$\varepsilon_{s, i j}=A_{s-g, i j} / L_{i j} \rho_{s} \mu_{s}$

$A_{s-g, i j}=\rho_{s, i j} \mu_{s} \varepsilon_{s} L_{i j}$

Finally, the gas holdup was determined using the expression

$\varepsilon_{g, i j}=1-\left(\frac{A_{s-g, i j}}{L_{i j} \rho_{s} \mu_{s}}\right)$.

\section{CT reconstruction algorithm}

The reconstruction algorithm proposed and used by Varma and Al-Dahhan [11], Varma et al. [12] was implemented to reconstruct the cross-sectional distribution of relative attenuation in a two-phase system. We proposed an alternating minimization (AM) algorithm based on turning a maximum likelihood problem into a double minimization of I-divergence introduced by Csiszár [13]. I-divergence is a measure of inconsistency between two functions, $a(y)$ and $b(y)$ [13], which is given as

$I(a \backslash \backslash b)=\sum_{y \in y} a(y) \ln \left[\frac{a(y)}{b(y)}\right]-\left[\sum_{y \in y}[a(y)-b(y)]\right]$,

where $Y$ is a finite dimensional space. The function $a(y)$ is taken to be the measured data, while $b(y)$ is taken to be a nonlinear model [14]. Let $q(y: \mu)$ be defined based on Beer Lambert's law for the transmission of photons [10], as follows:

$q(y: \mu)=I_{0}(y) \exp \left[-\sum_{x \in X} b(y / x) \mu(s)\right]$,

where $I_{0}(y)$ is the incident intensity, $b(y / x)$ the length of projection $y$ in pixel $x, q(y: \mu)$ represents the transmission of photons and is a function of the attenuation, and $b(y)$ represents a Poisson random number $d(y)$. Equation (1) can be rewritten as

$I\left(d \backslash q(y: \mu)=\sum_{y \in Y}\left\{\mathrm{~d}(y) \ln \frac{\mathrm{d}(y)}{q(y: \mu)}-[\mathrm{d}(y)-q(y: \mu)]\right\}\right)$.
The algorithm minimizes the left term in Eq. (12) with respect to the attenuation $(\mu)$. More details and mathematical proofs regarding the AM algorithm are available elsewhere [15]. In this work, the AM algorithm was used to reconstruct images that represent attenuation of the gassolid system. For local holdup/attenuation measurements computed tomography (CT) is used.

\section{$C T$ validation}

Before implementing the computed tomography (CT) technique, it is advisable to test the ability of the CT set-up to obtain the time-averaged cross-sectional and radial profile of phase holdup distribution by using phantom which is designed to represent multiphase systems. The object represented in Fig. 4a was made of perspex. The phantom consists of two sections. The inner section is a tube with $7.6 \mathrm{~cm}$ in diameter which is filled with air. The outer section is filled with water and has a diameter of $14 \mathrm{~cm}$. The dimensions of the phases obtained by CT were well close to the phantom's dimensions with discrepancy of $0.92 \%$ (see Fig. 4).

\section{Results and discussion}

\section{Reproducibility of CT measurements}

All CT scans were acquired at one fixed axial position, $\mathrm{H} / \mathrm{D}=1.7$ (fully developed region). CT measurements were repeated in the 14-cm diameter column with the glass bead-gas system on two successive days to demonstrate the reproducibility (runs no. 1 and no. 2 in Figs. 5 and 6). The time-averaged cross-sectional gas holdup distributions (Fig. 5) and the radial gas holdup profiles (Fig. 6) exhibit good reproducibility, Fig. 5a, b exhibits similar cross-sectional gas holdup distributions to those obtained for runs no. 1 and no. 2 , the results correspond to the superficial gas velocity of $25 \mathrm{~cm} / \mathrm{s}$ and the axial location of $\mathrm{H} / \mathrm{D}=1.7$ (from the distributor). At most radial positions, the radial gas holdup values were almost identical. The few differences were accepted because they were within $\pm 4.5 \%$ error.

Overall gas holdup was measured at the same operating conditions using bed expansion as another independent technique to estimate the accuracy of the holdup data reported in this paper. It was found that the difference between the cross-sectional averaged holdup obtained by $\mathrm{CT}$ and the overall holdup by bed expansion was about $4.7 \%$. 
Fig. 4 a Picture of $14 \mathrm{~cm}$ phantom (perspex) used in the CT scan experiments with two phases: (air in the inner tube and water in the outer section), $\mathbf{b}$ the mass attenuation coefficient distribution for the two phases Phantom

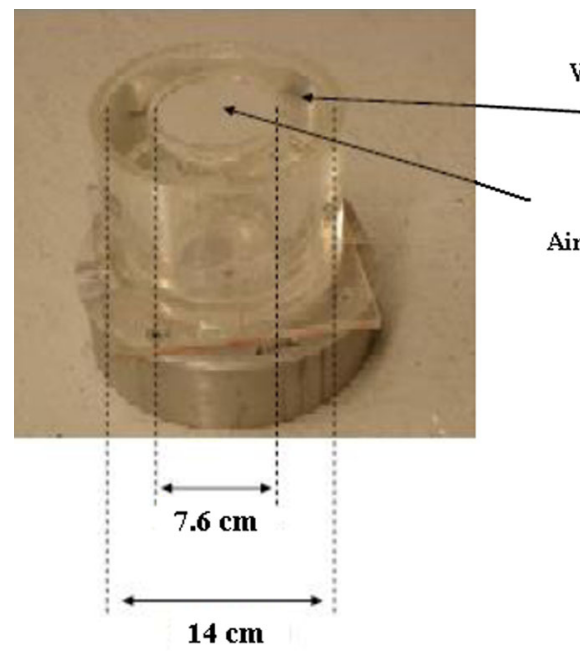

(a)

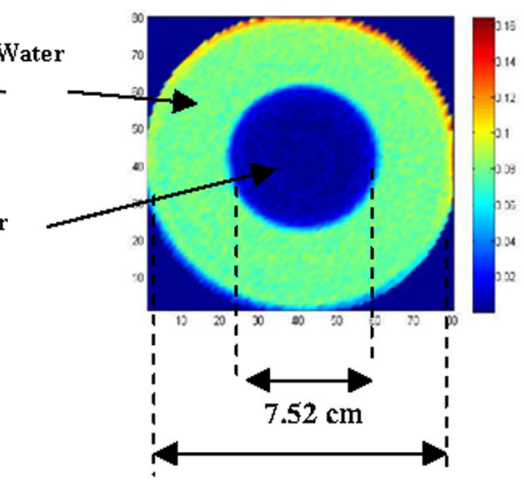

$13.9 \mathrm{~cm}$ (b)
Fig. 5 Reproducibility of CT measurements for crosssectional gas holdup distribution: glass beads-gas system, $\mathbf{a}$ run no. 1 , and $\mathbf{b}$ run no. 2

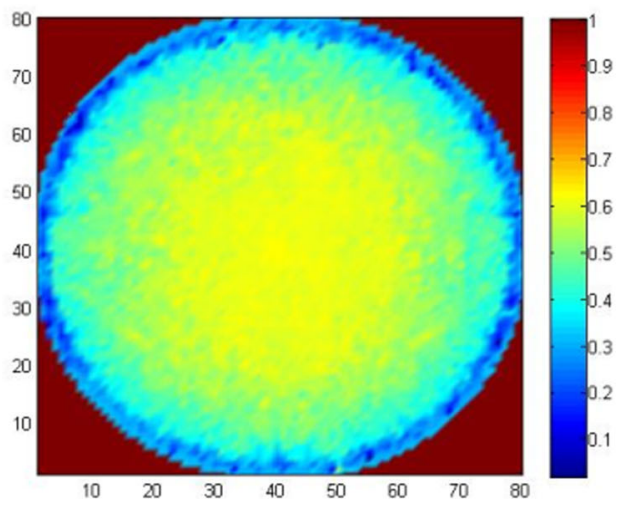

(a)

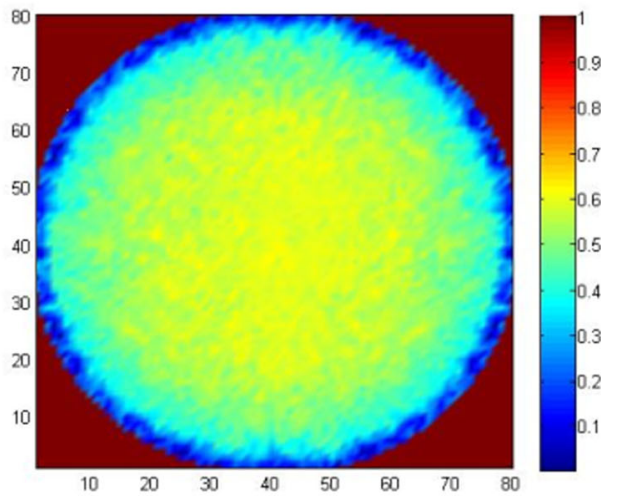

(b)

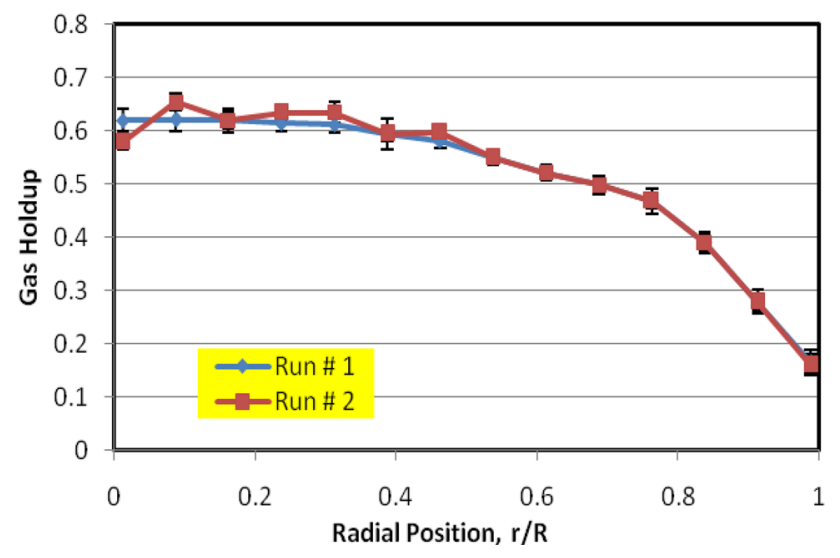

Fig. 6 Reproducibility of CT measurements for radial gas holdup profiles: superficial gas velocity $U g=25 \mathrm{~cm} / \mathrm{s}$; axial level $\mathrm{H} / \mathrm{D}=1.7$, glass beads-gas system

\section{Cross-sectional and radial profiles of phase holdups distribution}

The reconstructed image, processed from data obtained through CT scans, provides the cross-sectional time-averaged gas and solid holdups distribution. The effect of the superficial gas velocity on both the time-averaged gas and solid holdups (gas holdup + solid holdup $=1$ ), and radial profiles at different superficial gas velocities was investigated. An offering an idea of how gas and solid are distributed through the column (see Fig. 7). The change in the gas and solid holdup magnitude values was indicated by the color variation. Red indicates a higher gas holdup value while blue indicates a lower value of gas holdup. In general it can be observed that, gas holdup is higher in the center and lower near the wall. At lower superficial gas velocity, 

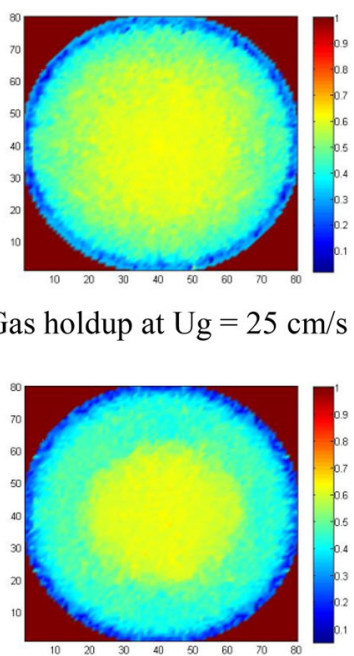

Gas holdup at $\mathrm{Ug}=30 \mathrm{~cm} / \mathrm{s}$

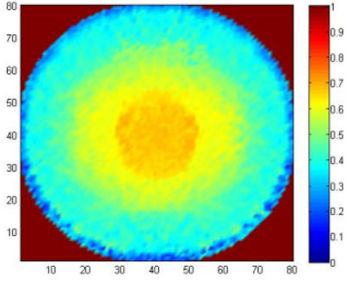

Gas holdup at $\mathrm{Ug}=25 \mathrm{~cm} / \mathrm{s}$

Gas holdup at $\mathrm{Ug}=35 \mathrm{~cm} / \mathrm{s}$

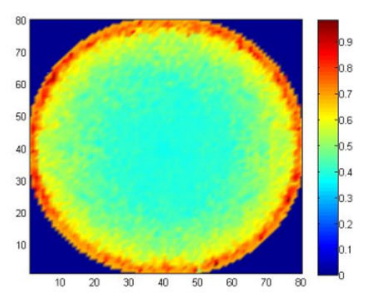

Solid holdup at $\mathrm{Ug}=25 \mathrm{~cm} / \mathrm{s}$

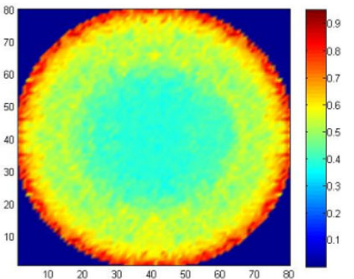

Solid holdup at $\mathrm{Ug}=30 \mathrm{~cm} / \mathrm{s}$

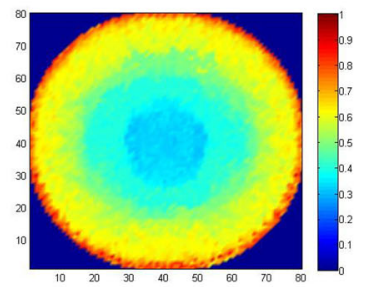

Solid holdup at $\mathrm{Ug}=35 \mathrm{~cm} / \mathrm{s}$
Fig. 7 Cross section gas and solid holdup for glass beads at different superficial gas velocities

relatively uniform distribution of gas holdup can be observed.

\section{Effect of gas velocity on time-average gas and solid holdups}

The effect of the superficial gas velocity on the time-averaged gas holdup radial profiles at different superficial gas velocities was investigated. The effect of increasing the superficial gas velocity at constant mass flux can be understood to decrease the solid holdup due to the increase in the solid velocity. Since the gas injection is the only source of energy that drives the solids. Therefore, with an increase in the superficial gas velocity, the magnitude of the value of the gas holdup (void fraction or volumetric gas fraction) increased along the radial position (gas holdup + solid holdup =1). The gas holdup (void fraction) data at specific axial position $(H / D=1.7)$ were averaged over the cross section by numerical integration based on the trapezoidal rule

$\bar{\varepsilon}=\frac{2}{R} \int_{0}^{R} \varepsilon(r) \mathrm{d} r$.

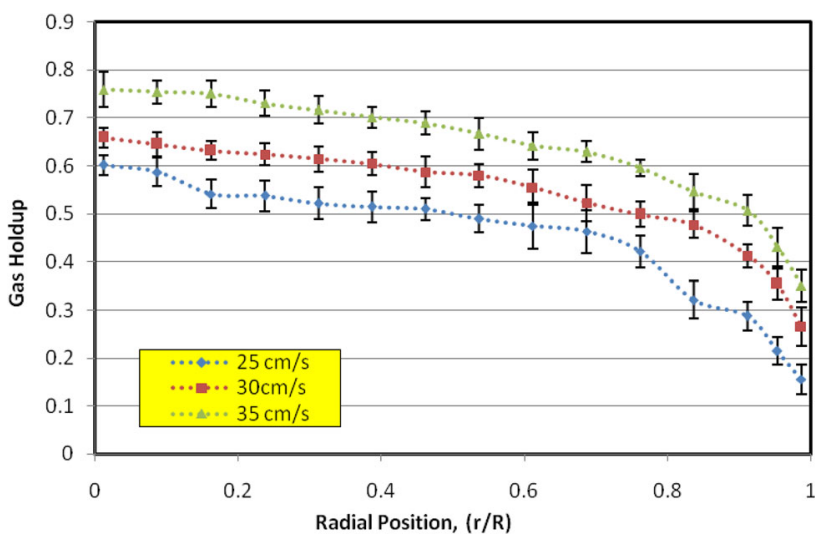

Fig. 8 Effect of superficial gas velocity on radial profiles of gas holdup

This cross-sectional averaged value (void fraction) was about 0.32 at superficial gas velocity $20 \mathrm{~cm} / \mathrm{s}$ and the magnitude of the gas holdup (void fraction) increased by 42 and $56 \%$ when the superficial gas velocity increased from 20 to $25 \mathrm{~cm} / \mathrm{s}$ and from 20 to $35 \mathrm{~cm} / \mathrm{s}$, respectively. Figure 8, shows that the local gas holdup was greater near the center-line of the bed compared to that near the wall; Fig. 7, shows the cross-sectional, time-averaged gas and solid holdup distributions obtained using the gamma ray computed tomography technique for glass bead particles at various superficial gas velocities $(25,30$, and $35 \mathrm{~cm} / \mathrm{s})$. The change in the gas holdup magnitude values was indicated by the color variation. It was observed that gas holdup increased as the superficial gas velocity increased; this was due to a higher volume of air passing through the bed, and confirms a trend identified by Mabrouk et al. [9]. In addition, increase in superficial gas velocity enhances mixing throughout the bed, and also increases the bed expansion and the overall gas holdup in the system. An image of this cross section is presented in Fig. 7; for $\mathrm{Ug}=25 \mathrm{~cm} / \mathrm{s}$, a high local gas holdup is concentrated in the center of the bed and extended to the region near the bed wall. This behavior indicates that the air is flowing throughout the bed.

Increasing the superficial gas velocity to $30 \mathrm{~cm} / \mathrm{s}$ enhances mixing throughout the bed, and higher gas holdup is located in the core of the bed, while lower solids holdup (solid concentration) is found along the bed walls, as can be seen in Fig. 7. This behavior indicates that, the air is flowing mostly through the center of the bed; the local gas holdup is more symmetrically distributed through the bed.

When the superficial gas velocity further increased, $(\mathrm{Ug}=35 \mathrm{~cm} / \mathrm{s}$ ), large bubbles erupted from the bed near the center, throwing glass beads against the wall, which fell 
back into the bed. These hydrodynamics created a high gas holdup region in the center of the bed, while lower gas holdup regions (higher solids concentration) were found along the bed walls.

To examine further the relationship between the changes of local gas concentration and changing of superficial gas velocity and spatial position, the representing probability density function (PDF) was studied. Figure 9 displays the probability density functions of the gas holdup distribution values in the pixel cells. PDF characterizes the gas holdup variation values along the pixel cells at different superficial gas velocities. The variation in the corresponding mean, variance, and standard deviation, which were directly calculated by MATLAB functions, increased with an increase in superficial gas velocity. The maximum variance of gas holdup was found to be less than $1.4 \%$, while the standard deviation varied less than $12 \%$.

\section{Effect of particle density on time-averaged gas and solid holdups}

The fluidization hydrodynamics of two bed materials (glass beads and copper particles) were compared in this study. Figures 10 and 11 show the reconstructed image for both glass beads-gas and copper particle-gas systems, respectively, at 25 and $30 \mathrm{~cm} / \mathrm{s}$ superficial gas velocity, respectively. Figure $12 \mathrm{a}, \mathrm{b}$ shows the time-averaged radial gas and solid holdup profiles obtained by averaging the data at $\mathrm{H} / \mathrm{D}=1.7$ (fully developed region) for both glass beadsgas and copper particle-gas systems, respectively, at $25 \mathrm{~cm} / \mathrm{s}$ superficial gas velocity, while Fig. 13a, b shows the time-averaged radial gas and solid holdup profiles obtained for both glass beads-gas and copper particle-gas systems, respectively, at $30 \mathrm{~cm} / \mathrm{s}$, superficial gas velocity. It can be observed that the local time-averaged gas holdup is a function of the bed material density, as the material density decreased, gas holdup increased and solid holdup decreased (gas holdup + solid holdup $=1$ ). The bed with copper particles was shown to have lower gas holdup than the glass bead bed, which exhibited a higher gas holdup. In addition Figs. 12 and 13 show that the general fluidization behavior was similar for glass beads and copper particles, with a region of higher gas holdup in the center, and a region of low gas holdup (higher solids concentration) near the walls. Similar results were revealed by Franka [16] for two different 3D beds and Escudero et al. [6].

\section{Conclusions}

This study is part of a much more extensive investigation that includes many laboratory experiments. High resolution gamma ray computed tomography was successfully applied

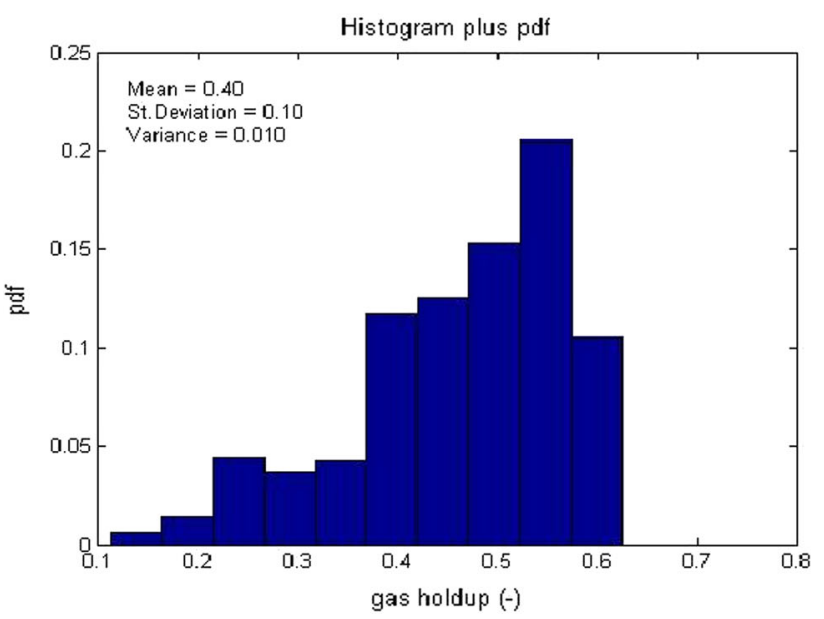

(a) $\mathrm{Ug}=25 \mathrm{~cm} / \mathrm{s}$

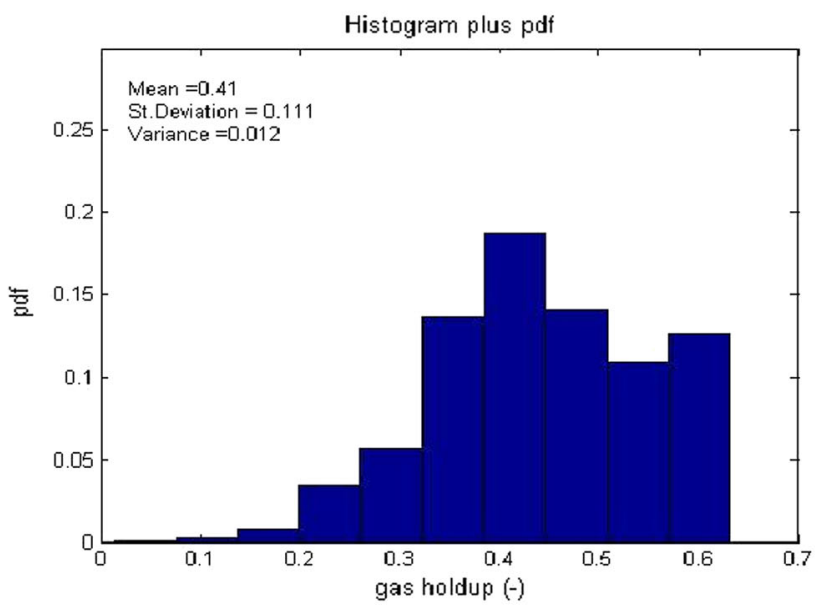

(b) $\mathrm{Ug}=30 \mathrm{~cm} / \mathrm{s}$

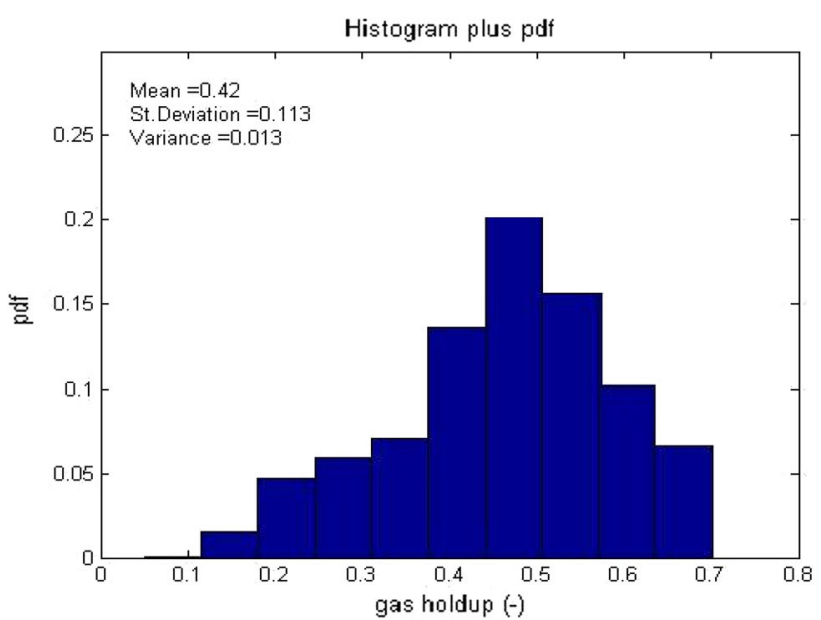

(c) $\mathrm{Ug}=35 \mathrm{~cm} / \mathrm{s}$

Fig. 9 Probability density function of the values of gas Holdup in the Pixel cells

for the determination of phases fraction distributions (gas holdup and solid holdup). The changes of local solids concentration reflect the interactions between gas and 


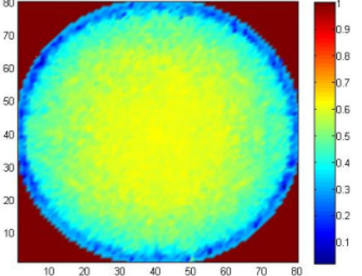

Gas holdup for glass beads at $\mathrm{Ug}=25 \mathrm{~cm} / \mathrm{s}$

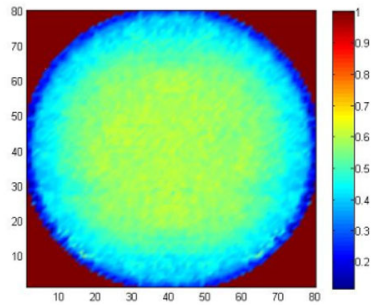

Gas holdup for copper at $\mathrm{Ug}=25 \mathrm{~cm} / \mathrm{s}$

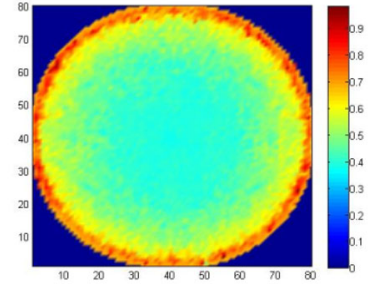

Solid holdup for glass beads

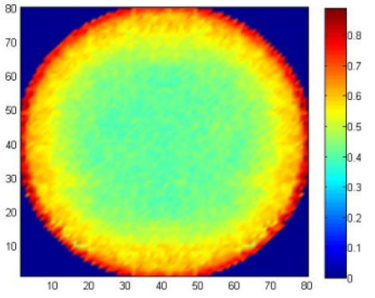

Solid holdup for copper at $\mathrm{Ug}=25 \mathrm{~cm} / \mathrm{s}$ at $\mathrm{Ug}=25 \mathrm{~cm} / \mathrm{s}$

Fig. 10 Time-averaged cross-sectional gas and solid holdup distribution for glass bead-gas and copper particle-gas systems respectively at $25 \mathrm{~cm} / \mathrm{s}$

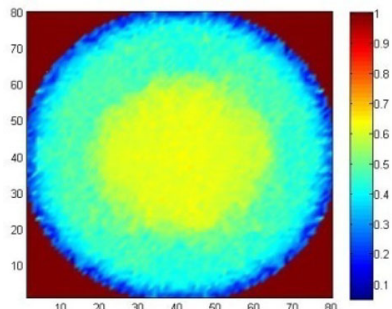

Gas holdup for glass beads at $\mathrm{Ug}=30 \mathrm{~cm} / \mathrm{s}$

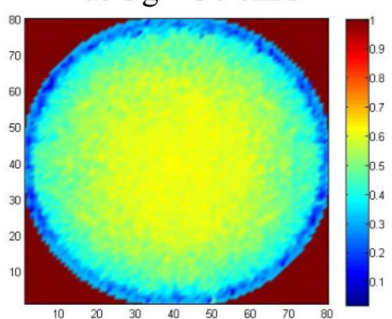

Gas holdup for copper at $\mathrm{Ug}=30 \mathrm{~cm} / \mathrm{s}$

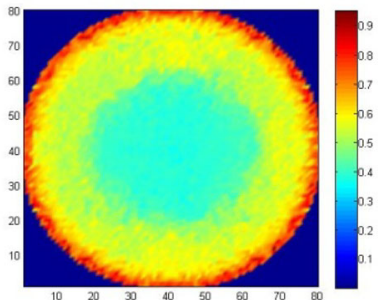

Solid holdup for glass beads at $\mathrm{Ug}=30 \mathrm{~cm} / \mathrm{s}$

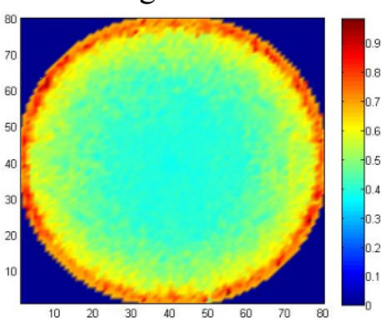

Solid holdup for copper at $\mathrm{Ug}=30 \mathrm{~cm} / \mathrm{s}$
Fig. 11 Time averaged cross-sectional gas and solid holdup distribution for glass bead-gas and copper particle-gas systems, respectively, at $30 \mathrm{~cm} / \mathrm{s}$

solids phase, which can influence the apparent reaction and mass and heat transfer in the fluidized beds, which furthermore can influence the overall reaction rate in fluidized reactors. Gamma ray CT is particularly useful in visualizing fluidized beds, and can provide a detailed 3-D timeaveraged density map of the flow structure. Time-averaged
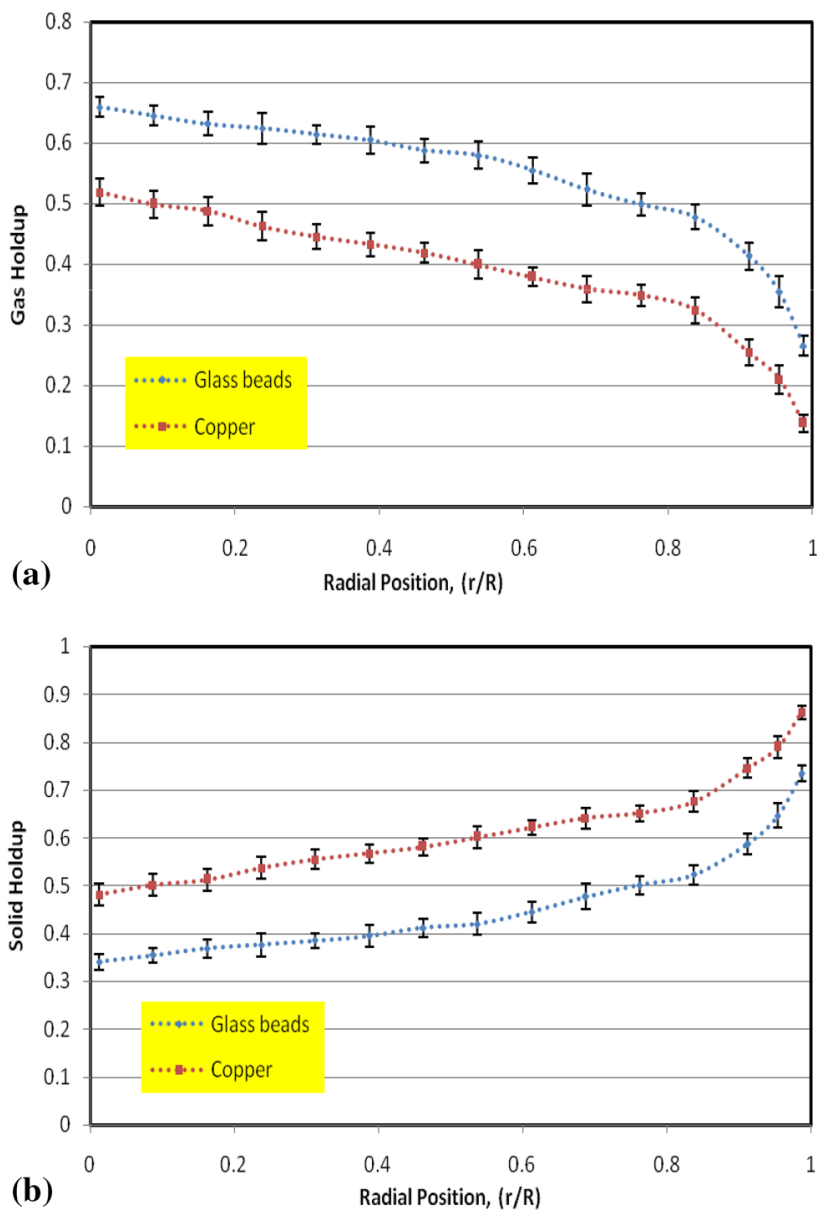

Fig. 12 Radial profiles of gas and solid holdups for glass beads and copper particle at $\mathrm{Ug}=25 \mathrm{~cm} / \mathrm{s}$

gas and solid holdup distributions were measured in a $14 \mathrm{~cm}$ fluidized bed column using gamma rays instead of $\mathrm{X}$-rays (due to the height attenuation of copper particles) at different superficial gas velocities, $(25,30$, and $35 \mathrm{~cm} / \mathrm{s})$, which cover the fluidization and bubbly flow regimes. To investigate the effect of superficial gas velocity and particle density on phase holdup distribution (gas holdup and solid holdup), glass beads and copper particles were used as the bed materials. It was observed that, the gas holdup increased with an increase in the superficial gas velocity. A rise in the superficial gas velocity was also found to affect the internal flow structure, enhancing mixing in the bed and producing a more homogenous bulk bed. In addition, while superficial gas velocity significantly affects fluidization hydrodynamics, it appears that changes in the superficial gas velocity do not significantly affect fluidization symmetry as it can be seen in Figs. 7, 10, and 11.

In addition, local time-averaged gas holdup is a function of bed material density, The two materials (glass beads and copper particles) exhibited a similar fluidization structure, with a region of higher gas holdup in the center and a 


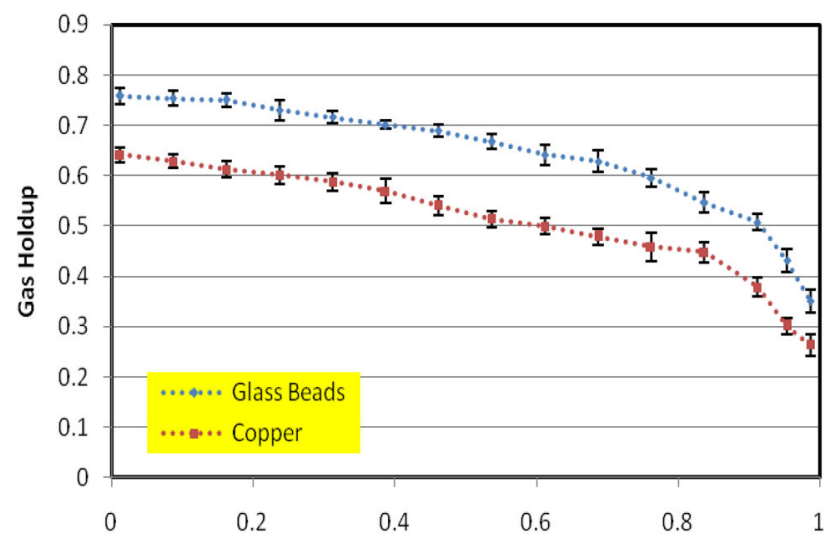

(a)

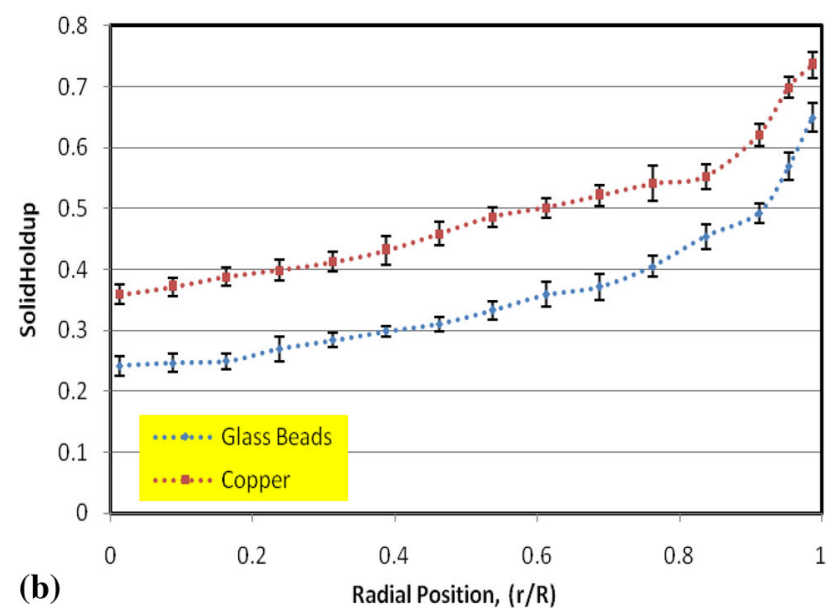

Fig. 13 Radial profiles of gas and solid holdups for glass beads and copper particle at $\mathrm{Ug}=30 \mathrm{~cm} / \mathrm{s}$

region of low gas holdup (higher solids concentration) near the walls.

Acknowledgments The authors wish to acknowledge the Libyan Ministry of Education for sponsoring the primary author's study within the Chemical Engineering Department at Missouri University of Science and Technology. The gamma ray facility and set-up used in this research was funded by Dr. Al-Dahhan.

Open Access This article is distributed under the terms of the Creative Commons Attribution 4.0 International License (http://crea tivecommons.org/licenses/by/4.0/), which permits unrestricted use, distribution, and reproduction in any medium, provided you give appropriate credit to the original author(s) and the source, provide a link to the Creative Commons license, and indicate if changes were made.

\section{References}

1. McCabe WE, Smith JC, Harriott P (2001) Unit operations of chemical engineering. Mc Graw Hill, New York

2. Fincke JR, Berggren MJ, Johnson SA (1980) The application of reconstructive tomography to the measurement of density distribution in two-phase flow. In: Proceedings of 26th international instrumentation symposium, Seattle, pp 235-243

3. Seville JPK, Morgan JEP, Clift R (1986) Tomographic determination of the voidage structure of gas fluidized beds in the jet region. In: Fluidization V: proceedings of 5th international conference Fluidization, Denmark

4. Banholzer WF, Spiro CL, Kosky PG, Maylotte DH (1987) Direct imaging of time-averaged flow patterns in a fluidized reactor using X-ray computed tomography. Ind Eng Chem Res 26(4):763-767

5. Grassler T, Wirth KE (2000) X-ray computer tomography-potential and limitation for the measurement of local solids distribution in circulating fluidized beds. Chem Eng J 77(1):65-72

6. Escudero D, Theodore J, Heindel JT (2011) Bed height and material density effects on fluidized bed hydrodynamics. Chem Eng Sci 66:3648-3655

7. Zhu H, Zhu J, Li G, Li F (2008) Detailed measurements of flow structure inside a dense gas-solid fluidized bed. Power Technol 180(3):339-349

8. Du B, Warsito W, Fan L-S (2003) Bed nonhomogeneity in turbulent gas-solid fluidization. AICHE J 49(5):1109-1126

9. Mabrouk R, Radmanesh R, Chaouki J, Guy C (2005) Scale effects on fluidized bed hydrodynamics. Int J Chem Reactor Eng 3:A18

10. Varma R (2008) Characterization of anaerobic bioreactors for bioenergy generation using a novel tomography technique, Ph.D. Thesis, Washington University in St. Louis, Saint Louis, Mo, USA

11. Varma R, Al-Dahhan M (2007) Effect of sparger design on hydrodynamics of a gas recirculation anaerobic bioreactor. Biotechnol Bioeng 98(6):1146-1160

12. Varma R, Bhusarapu S, O'Sullivan JA, Al-Dahhan MH (2007) A comparison of alternating minimization and expectation maximization algorithms for single source gamma ray tomography. Meas Sci Technol, 18(2007):1-13

13. Csiszár I (1991) Why least squares and maximum entropy? An axiomatic approach to inference for linear inverse problems. Ann Stat 19:2033-2066

14. Bhusarapu S, Al-Dahhan MH, Dudukovic MP (2006) Solids flow mapping in a gas-solid riser: mean holdup and velocity fields. Powder Technol 163(1-2):98-123

15. O'Sullivan JA, Benac J (2007) Alternating minimization algorithms for transmission tomography. IEEE Trans Med Imag 26(3):283-297

16. Franka NP (2008) Visualizing fluidized beds with X-rays, Master's Thesis, Iowa State University, Ames, IA 